\title{
Sodium Bicarbonate Sub-Diaphragmatic Irrigation Relieves Shoulder Pain After Total Laparoscopic Hysterectomy: A Randomized Controlled Trial
}

\author{
Li Liu (1D ${ }^{1, *}$ \\ Tian $\mathrm{Xia}^{2, *}$ \\ Haiyan Ji' \\ Yaxin Guo' \\ Junfeng Liu (D' \\ Liping $\mathrm{Du}{ }^{\prime}$ \\ Daoyun Lei $\mathbb{D}^{3}$ \\ Chao $\mathrm{Han}$ (D) \\ Tieliang $\mathrm{Ma}^{4}$ \\ 'Department of Anesthesiology, The \\ Affiliated Yixing Hospital of Jiangsu \\ University, Yixing, Jiangsu, People's \\ Republic of China; ${ }^{2}$ Department of \\ Gynaecology, The Affiliated Yixing \\ Hospital of Jiangsu University, Yixing, \\ Jiangsu, People's Republic of China; \\ ${ }^{3}$ Department of Anesthesiology, Zhongda \\ Hospital Southeast University, Nanjing, \\ jiangsu, People's Republic of China; \\ ${ }^{4}$ Central Laboratory, The Affiliated Yixing \\ Hospital of Jiangsu University, Yixing, \\ Jiangsu, People's Republic of China
}

*These authors contributed equally to this work
Study Objective: To determine whether sub-diaphragmatic irrigation with sodium bicarbonate would relieve post-laparoscopic shoulder pain (PLSP) after total laparoscopic hysterectomy.

Design: Randomized double-blinded trial.

Setting: Teaching hospital.

Patients: Seventy patients undergoing total laparoscopic hysterectomy (TLH) for benign indications.

Intervention: We randomly allocated patients to intervention or control groups where sodium bicarbonate containing flushing liquid or normal saline was irrigated sub-diaphragm before sewing.

Measurement \& Main Results: The primary outcome was PLSP following surgery measured by a numerical rating scale (NRS) $(0=$ no pain; $10=$ worst pain imaginable). Secondary outcomes were abdominal incisional and visceral pain, analgesic use, and sodium bicarbonate related side effects. The incidence of PLSP in intervention group was significantly lower than that in control group $(\mathrm{P}<0.05)$. Contrarily, incisional and visceral pain was similar in both groups $(\mathrm{P}=0.1)$. The consumption of rescue analgesics in the intervention group was lower than that in the control group. Side effects were comparable in both study groups.

Conclusion: Sub-diaphragmatic irrigation with sodium bicarbonate could effectively reduce shoulder pain, but not abdominal incisional and visceral pain, in patients undergoing TLH without an increase in side effects.

Registration information: Clinical trial registry number: http://www.chictr.org.cn/ (ChiCTR2100041765)

Registration findings: http://www.chictr.org.cn/showproj.aspx?proj=66721 Link to clinical trial page and data repository: http://www.medresman.org.cn/pub/cn/proj/projectshshow. aspx?proj=2992

Keywords: total laparoscopic hysterectomy, post-laparoscopic shoulder pain, sodium bicarbonate

\section{Introduction}

Laparoscopic surgery has been widely accepted in the diagnosis and management of gynecologic organ-related diseases, as it provides minimization of surgical wound, less postoperative pain, shorter hospital stay, rapid recovery, and a better cosmetic outcome, compared to conventional laparotomy. ${ }^{1,2}$ However, there are still $35 \%-80 \%$ of patients complaining of moderate to severe pain affects the quality of 
life within 3 days to a week after gynecologic laparoscopic surgery, resulting in delayed discharge or interference of coming back to normal activities., ${ }^{3,4}$

Laparoscopic gynecological surgery-related pain consists of skin incision (well localized), visceral organs (diffuse and poorly localized), and shoulder pain. ${ }^{5}$ The abdominal incisional and visceral pain appears immediately after the operation and non-steroidal anti-inflammatory drugs ${ }^{6}$ or local incisional infiltration ${ }^{7,8}$ are generally considered to be effective to alleviate the pain. However, post-laparoscopic shoulder pain (PLSP) is supposed to be referred pain due to carbon dioxide [CO2] pneumoperitoneum ${ }^{9}$ and occurs approximately 8 hours postoperatively, later than incisional pain, ${ }^{10}$ and displays less responsiveness to analgesics. ${ }^{4}$ Therefore, it is of great clinical significance to prevent PLSP.

Substantial evidence has shown that $\mathrm{CO} 2$ pneumoperitoneum be the main source of PLSP. ${ }^{9}$ Carbonic anhydrase located on the moist surface of the peritoneum and diaphragm converts $\mathrm{CO} 2$ to carbonic acid, resulting in a reduction in the peritoneal $\mathrm{pH}$ which irritates the peritoneal and diaphragmatic nerves, thus leading to PLSP. ${ }^{9,11}$ Elevating the $\mathrm{pH}$ value of the diaphragm might block the phrenic nerve stimulation induced by $\mathrm{CO} 2$ theoretically, which has been proved by the evidence of carbonic anhydrate inhibitor-acetazolamide in the reduction of PLSP dramatically. ${ }^{12}$

Sodium bicarbonate, a well-known alkaline liquid, is also used for peritoneal lavage in some specific cases, such as diffuse peritonitis-induced acid environment. ${ }^{13}$ Here, we hypothesize that sodium bicarbonate might neutralize the acid environment induced by $\mathrm{CO} 2$ pneumoperitoneum, and then relieve PLSP. The study was designed to determine whether sodium bicarbonate sub-diaphragmatic irrigation could reduce PLSP in patients undergoing total laparoscopic hysterectomy (TLH).

\section{Materials and Methods}

\section{Patients}

This randomized, double-blind, controlled trial was conducted at the Department of Anesthesiology, Affiliated Yixing Hospital of Jiangsu University, Yixing, China between December 2020 to April 2021. The study was approved by the ethics committee of the affiliated Yixing Hospital of Jiangsu University and registered as a clinical trial (trial registration number [chictr.org.cn] ID: ChiCTR2100041765). Raw data is available in medresman, http://www.medresman.org.

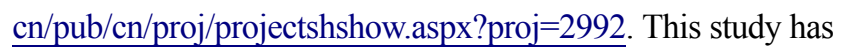

been performed consistent with the principles of the Helsinki Declaration on Human Experimentation.

Participants were recruited from a single-center gynecologic department at our unit. Consecutive patients scheduled for elective TLH under general anesthesia for benign indications (leiomyomas, endometriosis, abnormal uterine bleeding) were invited to participate in the study.

Eligible women were aged 20 to 80 years, American Society of Anesthesiologists (ASA) physical status classification I-II, no history of trauma or surgery, and be able to provide written informed consent.

Exclusion criteria were known allergy or contraindications to sodium bicarbonate, clinically significant cardiovascular or central nervous system disease, impaired renal or hepatic function, presence of pre-surgical shoulder pain or any acute or chronic pain syndromes, cognitive impairment or communications disorder, previous prescription of analgesic treatment, anxiety or depression (score $>8$ using Hospital Anxiety and Depression Scale (HADS) in a Chinese version), conversion to laparotomy, decline to participate. Furthermore, the patients with abdominal drainage, malignancy found on final pathology, and severe complications were also excluded.

\section{Sample Size Calculation}

We estimated the sample size at http://powerandsamplesize.

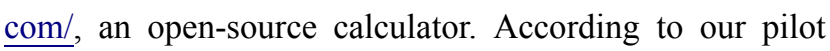
study, the incidence of PLSP in patients with sodium bicarbonate sub-diaphragmatic irrigation was $5 \%$, while $30 \%$ in control (data not published). To indicate a clinically significant reduction, a difference of $25 \%$ in the incidence of PLSP was considered appropriate for the sample size calculation. Given a power of $80 \%$ and a significance level of $5 \%$, the sample size was determined to be 66 , with 33 subjects in each arm using a 1:1 ratio for the groups. We added $15 \%$ for missing data or attritions, so a final sample size of 78 patients (39 patients per group) was recruited.

\section{Randomization}

The women were assigned randomly to the intervention/ control groups on the day the surgery took place by a research nurse on the basis of a randomization code developed by a computerized random number generators in balanced blocks of 6 . The allocation was concealed using opaque sequentially numbered sealed envelopes. The intervention group received sub-diaphragmatic Irrigation with $500 \mathrm{~mL} 1 \%$ sodium bicarbonate solution before suture, while control group equal volume normal saline. 


\section{Anesthesia and Surgery Protocol}

All patients received the same anesthetic scheme by a designated senior anesthesiologist. Standard monitoring was used including heart rate, respiratory rate, continuous ECG, SpO2, and non-invasive arterial blood pressure. General intravenous anesthesia was induced with midazolam $(0.3 \mathrm{mg} / \mathrm{kg})$, etomidate $(0.3 \mathrm{mg} / \mathrm{kg})$, fentanyl $(5 \mu \mathrm{g} / \mathrm{kg})$ and vecuronium $(0.15 \mathrm{mg} / \mathrm{kg})$. All patients were intubated and mechanically ventilated with $100 \%$ oxygen, VT 8 $10 \mathrm{~mL} / \mathrm{kg}$, frequency $10-14 / \mathrm{min}$, with an end-tidal CO2 of $30-40 \mathrm{mmHg}$ during the surgery procedure. Fentanyl $0.1 \mathrm{mg}$ was added before skin incision. The anesthesia was maintained with a continuous infusion of propofol 4-12 $\mathrm{mg} / \mathrm{kg} / \mathrm{h}$ and remifentanil $15-40 \mu \mathrm{g} / \mathrm{kg} / \mathrm{h}$, with the concentration titrated to hemodynamics stability and enough depth of anesthesia (BIS value between 40 and 60). The $\mathrm{CO} 2$ pneumoperitoneum pressure was maintained at $12 \mathrm{mmHg}$ with an inflation flow rate of $15 \mathrm{~L} / \mathrm{min}$. Ketorolac 30mg was given intravenously 5 minutes before sewing and the intravenous administration of anesthetics was stopped $5 \mathrm{~min}$ before the end of the operation. Reversal of residual neuromuscular blockade was done with a mixture of neostigmine $(0.02 \mathrm{mg} / \mathrm{kg})$ and atropine $(0.01 \mathrm{mg} / \mathrm{kg})$ and the patient was extubated. Patients were subsequently transferred to the ward after $15 \mathrm{~min}$ monitoring without a continuous postoperative analgesia program proposed by the anesthesiologist. Rescue analgesia was provided with ketorolac 30mg IV injection whenever the patient complained of a numerical rating scale (NRS) score equal to or more than 4 , and the maximum total daily was not allowed to exceed $120 \mathrm{mg}$.

A team of gynecologists experienced in laparoscopic surgery performed all procedures (4-port technique and vaginal cuff closed) and irrigated sub-diaphragm with blinded liquid before sewing in Trendelenburg position, while not pulmonary recruitment maneuvers but abdomenal compression was used to expel out of gas to minimize the residual gas within the abdominal cavity. Shoulder bracket was applied to support the shoulders during the procedure as well.

\section{Measures}

An independent research investigator, not involved in the operation and blinded to the patient's group, recorded NRS score of shoulder, incisional and visceral pain at fixed intervals, ie, immediately after extubation, 2, 6, 12, 24, 48, 72h postoperatively. Peri-operative vital signs, the dose of anesthetics, recovery time, tracheal extubation time, and rescue ketorolac were collected from the hospital database. As there were cases of critical alkalosis following intraperitoneal irrigation with sodium bicarbonate, ${ }^{14}$ we diluted the concentration of sodium bicarbonate in the flushing solution and performed blood gas analysis 10min after extubation. The results of blood gas analysis were also recorded. Any possible symptoms of alkalosis such as dyspnea, agitation, paresthesia, convulsions were collected as well.

\section{Statistical Analysis}

The normality assumption was assessed using the Kolmogorov-Smirnov test in all analyses. Continuous variables were presented as a mean (SD) or median (interquartile range), and categorical variables were presented as count and percentage. Group comparisons were made using 2 independent sample $t$ tests for continuous variables with a normal distribution, the Mann-Whitney $U$-test for continuous variables with a nonnormal distribution, or the $\chi^{2}$ test or Fisher exact test for dichotomous and ranked data. A two-tailed probability of $<0.05$ was considered statistically significant. We used SPSS (Statistical Package for the Social Science; SPSS Inc., Chicago, IL, USA) version 25 for all statistical analyses.

\section{Results}

A study flow diagram is shown in Figure 1. Of the 78 patients, eight participants were excluded due to conversion to laparotomy (1), abdominal drainage (4), malignancy outcome (2), and severe infection (1), and seventy cases were finally enrolled in this study, thirty-five in each group. No significant difference was found between the two groups in terms of demographic and clinic data including age, body mass index (BMI), smoking, alcohol, comorbidities (hypertension, diabetes mellitus), indications, pre-surgical hypogastralgia, duration of surgery and anesthesia and pneumoperitoneum, consumption of intra-operative propofol and remifentanil, blood loss, recovery time, tracheal extubation time, and stay of length ( $P>0.05$; Table 1), except for the cumulative rescue ketorolac consumption in the intervention group lower than in the control group $(\mathrm{P}<0.05$; Table 1).

Eleven patients in the control group presented with PLSP and three in the intervention group during 3 days after surgery. The incidence of PLSP in the intervention group was significantly lower than that in the control group ( $8.6 \%$ vs $31.4 \%, \mathrm{P}<0.05$; Table 2$)$. The median interquartile range (in centiles) of shoulder pain score 


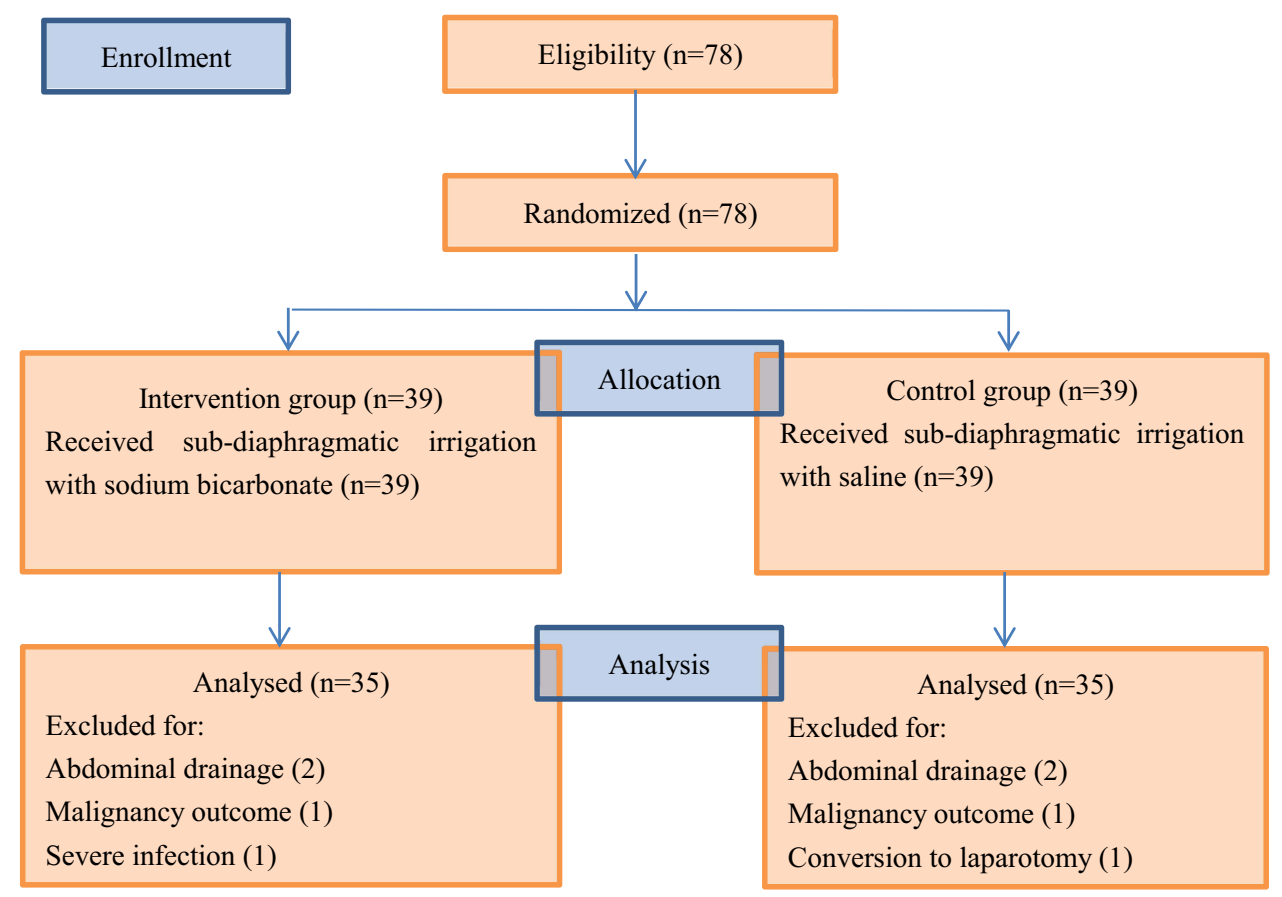

Figure I Flowchart showing the enrollment of participants to the study groups.

immediately after extubation, 2, 6, 12, 24, 48, and 72 $\mathrm{h}$ postoperatively in the intervention group was $0.0(0.0$ $0.0), 0.0(0.0-0.0), 0.0(0.0-0.0), 0.0(0.0-0.0), 0.0(0.0-0.0)$, $0.0(0.0-0.0)$, and $0.0(0.0-0.0)$ respectively. The value in the control group were $0.0(0.0-0.0), 0.0(0.0-0.0), 0.0(0.0-$ $1.0), 0.0(0.0-2.0), 0.0(0.0-1.0), 0.0(0.0-1.0), 0.0(0.0-0.0)$, respectively. The median interquartile range of shoulder pain score $6,12,24$, and $48 \mathrm{~h}$ postoperatively was significantly low in the intervention group as compared to control group ( $\mathrm{p}=0.018,0.015,0.019,0.006$ at $6,12,24$ and $48 \mathrm{~h}$, respectively, Table 2 ). In addition, the pain distribution was dominated in right shoulder and no difference was found in both groups (intervention group vs control group, $63.6 \%$ vs $66.7 \%, \mathrm{P}>0.05$ ). The postoperative abdominal incisional and visceral pain at all timepoints were comparable between the two groups (Table 2).

There were also no significant differences in arterial blood gas analyses ( $>0.05$; Table 3$)$. One patient in the intervention group presented with symptoms of weakness within $6 \mathrm{~h}$ after the surgery, and spontaneously resolved without any specific treatment within $12 \mathrm{~h}$. We did not observe any other complications.

\section{Discussion}

In the current study, sodium bicarbonate sub-diaphragmatic irrigation reduced the incidence and severity of PLSP during
3 days after TLH. The result is consistent with the study by Saadati $\mathrm{K}$ et al, ${ }^{15}$ in which peritoneal irrigation with sodium bicarbonate reduced the intensity of PLSP in patients undergoing laparoscopic cholecystectomy. On the other hand, the administration of sodium bicarbonate did not show an impact on incisional and visceral pain following surgery. Additionally, we did not found a significant difference in blood gas analysis and any serious complications. Therefore, sodium bicarbonate sub-diaphragmatic irrigation is an effective and safe method to prevent shoulder pain following laparoscopic hysterectomy.

Five aetiologies have been proposed for the underlying cause of PLSP including carbonic acid production, microvascular peritoneal hemorrhages, peritoneal dehydration and damage, visceral ligament traction, and neuropraxia. ${ }^{11}$ Besides, arm abduction and muscle pain associated with succinylcholine, a depolarizing muscle relaxant, might be relevant to shoulder pain following follow laparoscopy. ${ }^{9}$ However, none of the abovementioned reasons can alone explain the phenomenon.

Previous studies mostly focused on the reversion of the physical effects of $\mathrm{CO} 2$ pneumoperitoneum. Increasing intra-abdominal pressure during procedure causes the loss of a "suction" effect between the liver and diaphragm, allowing traction on the triangular and coronary ligaments of the liver that leads to PLSP. ${ }^{9,11,16}$ The patients 
Table I Demographic and Clinic Data in the Two Groups

\begin{tabular}{|c|c|c|c|}
\hline Variable & Intervention Group $(n=35)$ & Control Group $(n=35)$ & $P$ value \\
\hline \multicolumn{4}{|l|}{ Preoperative demographic data } \\
\hline Age(years) & $50.7 \pm 6.2$ & $50.5 \pm 5.8$ & 0.6 \\
\hline BMI(kg/m2) & $23.8 \pm 2.9$ & $24.5 \pm 3.9$ & 0.3 \\
\hline $\begin{array}{l}\text { ASA classification } \\
\text { II }\end{array}$ & $\begin{array}{l}16(45.6 \%) \\
19(54.4 \%)\end{array}$ & $\begin{array}{l}17(48.6 \%) \\
18(51.4 \%)\end{array}$ & 0.8 \\
\hline $\begin{array}{l}\text { Education } \\
\text { Illiteracy } \\
\text { Elementary education } \\
\text { High school and above }\end{array}$ & $\begin{array}{l}\mathrm{I}(2.9 \%) \\
3 \mathrm{I}(88.6 \%) \\
3(8.6 \%)\end{array}$ & $\begin{array}{l}2(5.7 \%) \\
30(85.7 \%) \\
3(8.6 \%)\end{array}$ & 0.8 \\
\hline $\begin{array}{l}\text { Employment } \\
\text { Employed } \\
\text { Housewife } \\
\text { Retired }\end{array}$ & $\begin{array}{l}23(65.7 \%) \\
8(22.9 \%) \\
4(11.4 \%)\end{array}$ & $\begin{array}{l}22(62.9 \%) \\
9(25.7 \%) \\
4(I 1.4 \%)\end{array}$ & 0.9 \\
\hline Smoking & $2(5.7 \%)$ & $\mathrm{I}(2.9 \%)$ & 0.6 \\
\hline Alcohol & $\mathrm{I}(2.9 \%)$ & $\mathrm{I}(2.9 \%)$ & I \\
\hline Hypertension & $8(22.9 \%)$ & $7(20.0 \%)$ & 0.7 \\
\hline DM & $2(5.7 \%)$ & $2(5.7 \%)$ & 1 \\
\hline \multicolumn{4}{|l|}{ Indications } \\
\hline Leiomyomas & $21(60.0 \%)$ & $24(68.6 \%)$ & 0.08 \\
\hline Endometriosis & $\mathrm{II}(3 \mathrm{I} .4 \%)$ & $10(28.6 \%)$ & 0.2 \\
\hline Abnormal uterine bleeding & $3(8.6 \%)$ & $\mathrm{I}(2.8 \%)$ & 0.3 \\
\hline Pre-surgical hypogastralgia & $8(22.9 \%)$ & $\mathrm{II}(3 \mathrm{I} .4 \%)$ & 0.4 \\
\hline \multicolumn{4}{|l|}{ Perioperative variables } \\
\hline Duration of surgery(min) & $135.3 \pm 63.2$ & $122.7 \pm 55.7$ & 0.4 \\
\hline Duration of anesthesia(min) & $145.9 \pm 62.8$ & $|36.| \pm 56 . \mid$ & 0.5 \\
\hline Duration of pneumoperitoneum(min) & $116.6 \pm 63.2$ & $111.9 \pm 54.9$ & 0.7 \\
\hline Consumption of propofol(mg) & $86.6 \pm 24.6$ & $75.4 \pm 30.0$ & 0.1 \\
\hline Consumption of remifentanil $(\mu \mathrm{g})$ & $241.9 \pm 67.5$ & $220.1 \pm 86.0$ & 0.3 \\
\hline Loss of blood(mL) & $69.4 \pm 39.3$ & $75.7 \pm 34.6$ & 0.5 \\
\hline Recovery time(min) & $13.2 \pm 5.4$ & $12.4 \pm 4.9$ & 0.5 \\
\hline Tracheal extubation time(min) & $14.7 \pm 5.0$ & $13.9 \pm 4.6$ & 0.5 \\
\hline Rescue ketorolac(mg) & $36.0 \pm 21.3$ & $55.7 \pm 33.0$ & 0.005 \\
\hline Stay of length(d) & $9.6 \pm 1.4$ & $9.9 \pm 1.6$ & 0.4 \\
\hline
\end{tabular}

Note: Values are presented as mean \pm SD or $n(\%)$.

Abbreviations: BMI, body mass index; DM, diabetes mellitus.

undergoing low-pressure laparoscopic surgery had signifi- a contributing factor and positively correlated with the cantly lower PLSP scores. ${ }^{17}$ Moreover, the volume of intensity of PLSP. ${ }^{18,19}$ Therefore, evacuating residual residual pneumoperitoneum has been proved as CO2 to prevent PLSP is likely the first precaution. 
Table 2 Shoulder, Incisional and Visceral Pain Score in Both Groups

\begin{tabular}{|c|c|c|c|}
\hline Variable & Intervention Group $(n=35)$ & Control Group $(n=35)$ & $P$ value \\
\hline \multicolumn{4}{|l|}{ Shoulder pain } \\
\hline NRS score immediately after extubation & $0.0(0.0-0.0)$ & $0.0(0.0-0.0)$ & I \\
\hline NRS score $2 \mathrm{~h}$ after surgery & $0.0(0.0-0.0)$ & $0.0(0.0-0.0)$ & 0.3 \\
\hline NRS score $6 \mathrm{~h}$ after surgery & $0.0(0.0-0.0)$ & $0.0(0.0-1.0)$ & 0.018 \\
\hline NRS score $12 \mathrm{~h}$ after surgery & $0.0(0.0-0.0)$ & $0.0(0.0-2.0)$ & 0.015 \\
\hline NRS score $24 \mathrm{~h}$ after surgery & $0.0(0.0-0.0)$ & $0.0(0.0-1.0)$ & 0.019 \\
\hline NRS score $48 \mathrm{~h}$ after surgery & $0.0(0.0-0.0)$ & $0.0(0.0-1.0)$ & 0.006 \\
\hline NRS score $72 \mathrm{~h}$ after surgery & $0.0(0.0-0.0)$ & $0.0(0.0-0.0)$ & 0.07 \\
\hline \multicolumn{4}{|l|}{ Incisional pain } \\
\hline NRS score immediately after extubation & $3.0(1.0-5.0)$ & $4.0(2.5-5.0)$ & 0.8 \\
\hline NRS score $2 \mathrm{~h}$ after surgery & $3.0(0.0-5.0)$ & $3.0(2.0-5.0)$ & 0.7 \\
\hline NRS score $6 \mathrm{~h}$ after surgery & $3.0(1.5-5.0)$ & $3.0(1.5-3.0)$ & 0.1 \\
\hline NRS score $12 \mathrm{~h}$ after surgery & $2.0(0.0-3.0)$ & $2.0(0.0-3.0)$ & 0.8 \\
\hline NRS score $24 \mathrm{~h}$ after surgery & $1.0(0.0-3.0)$ & $1.0(0.0-3.0)$ & I \\
\hline NRS score $48 \mathrm{~h}$ after surgery & $0.0(0.0-1.0)$ & $0.0(0.0-0.5)$ & 0.8 \\
\hline NRS score $72 \mathrm{~h}$ after surgery & $0.0(0.0-0.0)$ & $0.0(0.0-0.0)$ & 0.8 \\
\hline \multicolumn{4}{|l|}{ Visceral pain } \\
\hline NRS score immediately after extubation & $0.0(0.0-3.0)$ & $0.0(0.0-0.0)$ & 0.3 \\
\hline NRS score $2 \mathrm{~h}$ after surgery & $0.0(0.0-3.0)$ & $0.0(0.0-2.5)$ & 0.8 \\
\hline NRS score $6 \mathrm{~h}$ after surgery & $0.0(0.0-2.5)$ & $0.0(0.0-2.0)$ & 0.8 \\
\hline NRS score $12 \mathrm{~h}$ after surgery & $0.0(0.0-2.5)$ & $0.0(0.0-3.0)$ & 0.5 \\
\hline NRS score $24 \mathrm{~h}$ after surgery & $0.0(0.0-2.0)$ & $0.0(0.0-2.5)$ & 0.7 \\
\hline NRS score $48 \mathrm{~h}$ after surgery & $0.0(0.0-2.0)$ & $0.0(0.0-2.5)$ & 0.6 \\
\hline NRS score $72 \mathrm{~h}$ after surgery & $0.0(0.0-1.0)$ & $0.0(0.0-1.0)$ & 0.8 \\
\hline
\end{tabular}

Note: Values are presented as Median (IQR) 50th percentile (25th-75th).

Abbreviation: NRS, numerical rating scale.

Table 3 Marker of Blood Gas Analysis in the Two Groups

\begin{tabular}{|l|l|l|l|}
\hline Variable & Intervention Group $(\mathbf{n}=\mathbf{3 5})$ & Control Group $(\mathbf{n}=\mathbf{3 5})$ & P value \\
\hline $\mathrm{PH}$ & $7.41 \pm 0.07$ & $7.35 \pm 0.05$ & 0.5 \\
$\mathrm{HCO} 3^{-}$ & $25.0 \pm 1.4$ & $23.9 \pm 1.6$ & 0.7 \\
$\mathrm{~K}^{+}$ & $3.4 \pm 0.2$ & $3.4 \pm 0.2$ & 0.8 \\
$\mathrm{PO}_{2}$ & $94.2 \pm 10.5$ & $100.2 \pm 13.6$ & 0.3 \\
$\mathrm{PCO}_{2}$ & $38.4 \pm 4.8$ & $42.5 \pm 6.9$ & 0.9 \\
\hline
\end{tabular}

Abbreviations: $\mathrm{PH}$, potential of hydrogen; $\mathrm{HCO}$-, bicarbonate ion; $\mathrm{K}+$, kalium anion; PO2, partial pressure of oxygen; PCO2, partial pressure of carbon dioxide.

Varied approaches based on removing $\mathrm{CO} 2$ include pulmonary recruitment maneuver (PRM), ${ }^{20-22}$ intraperitoneal normal saline infusion, ${ }^{23}$ and both combined. ${ }^{24,25}$ Furthermore, the application of body position change to facilitate gas drain is also effective to reduce PLSP. ${ }^{26-28}$ However, the therapeutic potential of all these strategies needs support from the evidence from large-size sample clinical studies.

Some other studies investigated the role of local intraperitoneal anesthesia in the reduction of PLSP. ${ }^{29-31}$ Local intraperitoneal administration of anesthetic might cause a reversible interruption of nervous conduction, subsequently, inhibit the visceral afferent signaling, and reduce the shoulder pain. However, the results of these studies was not consistent. ${ }^{31}$ Local anesthetic toxicity and postoperative nausea and vomiting remain the main reason limiting its further application. ${ }^{32}$ Phrenic nerve block targeted on the irritation of $\mathrm{CO} 2$ insufflation to the subdiaphragmatic intra-peritoneal surface has also been shown to prevent PLSP effectively. ${ }^{33}$

In our study, the incidence of PLSP in the saline group was $31.4 \%$, lower than $80 \%$ reported in some known 
literature. ${ }^{4}$ We contributed it to strict patient selection, excellent anesthesia and analgesia program, experienced gynecologists, and appropriate pneumoperitoneum pressure. Intra-peritoneal normal saline infusion could also remove $\mathrm{CO} 2$ from the abdominal cavity to decrease PLSP. $^{23}$ The different distribution of pain between left and right shoulders indicated that the acid intraperitoneal environment caused by $\mathrm{CO} 2$ insufflation was not the only cause of shoulder pain. PLSP is therefore assumed as a multifactorial result in nature.

Homogenizing patients to highlight the role of sodium bicarbonate sub-diaphragmatic irrigation was the merit of the study design. However, there were some limitations in the study. First of all, we did not analyze the sub-population of age and duration of operative time, which had been reported as the risk factors of PLSP. ${ }^{34}$ Secondly, TLH related perineal pain be not included in the present study despite of causing discomfort to patients to some extent. Furthermore, the sample size was still small, although the number had been calculated in a statistical manner.

In summary, sub-diaphragmatic irrigation with sodium bicarbonate could decrease the intensity of shoulder pain during 3 days following TLH, but it had no impact on incisional and visceral pain without an increase in side effects. Our study indicated that sodium bicarbonate subdiaphragmatic irrigation might be an effective and safe method to reduce PLSP.

\section{Acknowledgments}

This work was supported by the General Program of Health Commission of Wuxi (grant number, MS201934) and Double hundred top talent project of Wuxi (grant number, HB2020109).

\section{Disclosure}

The authors report no conflicts of interest in this work.

\section{References}

1. Wadlund DL. Laparoscopy: risks, benefits and complications. Nurs Clin North Am. 2006;41(2):219-229. doi:10.1016/j.cnur.2006.01.003

2. Scheib SA, Thomassee M, Kenner JL. Enhanced recovery after surgery in gynecology: a review of the literature. J Minim Invasive Gynecol. 2019;26(2):327-343. doi:10.1016/j.jmig.2018.12.010

3. Craciunas L, Stirbu L, Tsampras N. The use of a peritoneal gas drain following gynecological laparoscopy: a systematic review. Eur J Obstet Gynecol Reprod Biol. 2014;179:224-228. doi:10.1016/j. ejogrb.2014.04.012

4. Lee DH, Song T, Kim KH, et al. Incidence, natural course, and characteristics of postlaparoscopic shoulder pain. Surg Endosc. 2018;32(1):160-165. doi:10.1007/s00464-017-5651-5
5. Choi JB, Kang K, Song MK, et al. Pain characteristics after total laparoscopic hysterectomy. Int $J$ Med Sci. 2016;13(8):562-568. doi:10.7150/ijms. 15875

6. Zhang H, Liu X, Jiang H, et al. Parecoxib increases muscle pain threshold and relieves shoulder pain after gynecologic laparoscopy: a randomized controlled trial. J Pain Res. 2016;13(9):653-660. doi:10.2147/JPR.S115889

7. Loizides S, Gurusamy KS, Nagendran M, et al. Wound infiltration with local anaesthetic agents for laparoscopic cholecystectomy. Cochrane Database Syst Rev. 2014;12(3):CD007049.

8. Ismet Hortu UT, Terzi H, Kale A, et al. Impact of bupivacaine injection to trocar sites on postoperative pain following laparoscopic hysterectomy: results from a prospective, multicentre, double-blind randomized controlled trial. Eur J Obstet Gynecol Reprod Biol. 2020;252:317-322. doi:10.1016/j.ejogrb.2020.07.007

9. Sao C-H, Chan-Tiopianco M, Chung K-C, et al. Pain after laparoscopic surgery: focus on shoulder-tip pain after gynecological laparoscopic surgery. $J$ Chin Med Assoc. 2019;82(11):819-826. doi:10.1097/JCMA.0000000000000190

10. Kaushal-Deep SM, Lodhi M, Anees A. Evolution of Various Components of Pain After Laparoscopic Cholecystectomy: importance of Its Prognostication for Effective Pain Control Using a Local Anesthetic and for Making a Valid Practical "Discharge Criteria" Model Predicting Early Discharge of Patients. J Laparoendosc Adv Surg Tech A. 2018;28(4):389-401. doi:10.1089/lap.2017.0530

11. Kaloo P, Armstrong S, Kaloo C, et al. Interventions to reduce shoulder pain following gynaecological laparoscopic procedures. Cochrane Database Syst Rev. 2019;1(1):CD011101. doi:10.1002/ 14651858.CD011101.pub2

12. Bala I, Bhatia N, Mishra P, et al. Comparison of preoperative oral Acetazolamide and intraperitoneal normal saline irrigation for reduction of postoperative pain after laparoscopic cholecystectomy. $J$ Laparoendosc Adv Surg Tech A. 2015;25(4):285-290. doi:10.1089/lap.2014.0507

13. Imhof M, Schmidt E, Bruch HP, et al. New therapeutic aspects in the treatment of diffuse peritonitis. Chirurg. 1987;58(9):590-593.

14. Shirasawa Y, Orita $\mathrm{H}$, Ishida $\mathrm{K}$, et al. Critical alkalosis following intraperitoneal irrigation with sodium bicarbonate in a patient with pseudomyxoma peritonei. $J$ Anesth. 2008;22(3):278-281. doi:10.1007/s00540-008-0612-8

15. Saadati K, Razavi MR, Salman DN, et al. Postoperative pain relief after laparoscopic cholecystectomy: intraperitoneal sodium bicarbonate versus normal saline. Gastroenterol Hepatol Bed Bench. 2016;9 (3):189-196.

16. Berberoğlu M, Dilek ON, Ercan F, et al. The effect of CO2 insufflation rate on the postlaparoscopic shoulder pain. $J$ Laparoendosc $A d v$ Surg Tech A. 1998;8(5):273-277. doi:10.1089/lap.1998.8.273

17. Sroussi J, Elies A, Rigouzzo A, et al. Low pressure gynecological laparoscopy $(7 \mathrm{mmHg})$ with AirSeal ${ }^{\circledR}$ System versus a standard insufflation $(15 \mathrm{mmHg})$ : a pilot study in 60 patients. J Gynecol Obstet Hum Reprod. 2017;46(2):155-158. doi:10.1016/j.jogoh.2016.09.003

18. Song T, Kim KH, Lee KW. The intensity of postlaparoscopic shoulder pain is positively correlated with the amount of residual pneumoperitoneum. J Minim Invasive Gynecol. 2017;24(6):984-989. doi:10.1016/j.jmig.2017.06.002

19. Sabzi Sarvestani A, Zamiri M. Residual pneumoperitoneum volume and postlaparoscopic cholecystectomy pain. Anesth Pain Med. 2014;4(4):e17366. doi:10.5812/aapm.17366

20. Pergialiotis V, Vlachos DE, Kontzoglou K, et al. Pulmonary recruitment maneuver to reduce pain after laparoscopy: a meta-analysis of randomized controlled trials. Surg Endosc. 2015;29(8):2101-2108. doi:10.1007/s00464-014-3934-7

21. Lee J, Park C, Kim J, et al. Effect of low-pressure pulmonary recruitment maneuver on postlaparoscopic shoulder pain: randomized controlled trial. J Minim Invasive Gynecol. 2020;27(1):173-177. doi:10.1016/j.jmig.2019.03.020 
22. Yilmaz G, Kiyak H, Akca A, et al. Low-pressure pulmonary recruitment maneuver: equal to or worse than moderate-pressure pulmonary recruitment maneuver in preventing postlaparoscopic shoulder pain? A randomized controlled trial of 72 patients. Wideochir Inne Tech Maloinwazyjne. 2020;15(3):519-525. doi:10.5114/wiitm.2019.89831

23. Tsai HW, Chen YJ, Ho CM, et al. Maneuvers to decrease laparoscopy-induced shoulder and upper abdominal pain: a randomized controlled study. Arch Surg. 2011;146(12):1360-1366. doi:10.1001/archsurg.2011.597

24. Tsai HW, Wang PH, Yen MS, et al. Prevention of postlaparoscopic shoulder and upper abdominal pain: a randomized controlled trial. Obstet Gynecol. 2013;121(3):526-531. doi:10.1097/AOG.0b01 $3 \mathrm{e} 318283 \mathrm{fcca}$

25. Kumari A, Rajaram S, Gupta B, et al. Assessment of a combination of clinical maneuvers in evaluation of post-laparoscopic pain: a randomized clinical trial. J Obstet Gynaecol India. 2019;69 (5):444-450. doi:10.1007/s13224-019-01224-4

26. Kiyak H, Yilmaz G, Necmiye A. Semi-Fowler positioning in addition to the pulmonary recruitment manoeuvre reduces shoulder pain following gynaecologic laparoscopic surgery. Wideochir Inne Tech Maloinwazyjne. 2019;14(4):567-574. doi:10.5114/wiitm.2019.84384

27. van Dijk JEW, Dedden SJ, Geomini PMAJ, et al. POstLAparoscopic Reduction of pain By combining intraperitoneal normal salinE And the pulmonary Recruitment maneuver (POLAR BEAR trial). RCT to estimate reduction in pain after laparoscopic surgery when using a combination therapy of intraperitoneal normal saline and the pulmonary recruitment maneuver. BMC Womens Health. 2017;17(1):42. doi:10.1186/s12905-017-0397-8

28. Phelps P, Cakmakkaya OS, Apfel CC, et al. A simple clinical maneuver to reduce laparoscopy-induced shoulder pain: a randomized controlled trial. Obstet Gynecol. 2008;111(5):1155-1160. doi:10.1097/AOG.0b013e31816e34b4
29. Kaushal-Deep SM, Anees A, Khan S, Khan MA, Lodhi M. Randomized controlled study of intraincisional infiltration versus intraperitoneal instillation of standardized dose of ropivacaine $0.2 \%$ in post-laparoscopic cholecystectomy pain: do we really need high doses of local anesthetics-time to rethink! Surg Endosc. 2018;32 (7):3321-3341. doi:10.1007/s00464-018-6053-z

30. El-labban G, El-labban M, Saadl S, Hokkam E, Morsy K, Heissam K. Intraincisional vs intraperitoneal infiltration of local anaesthetic for controlling early post-laparoscopic cholecystectomy pain. J Minim Access Surg. 2011;7(3):173-177. doi:10.4103/0972-9941.83508

31. Jain S, Nazir N, Singh S, et al. A prospective randomised controlled study for evaluation of high-volume low-concentration intraperitoneal bupivacaine for post-laparoscopic cholecystectomy analgesia. Indian J Anaesth. 2018;62(2):109-114. doi:10.4103/ija.IJA_87_17

32. Marks JL, Ata B, Tulandi T. Systematic review and metaanalysis of intraperitoneal instillation of local anesthetics for reduction of pain after gynecologic laparoscopy. J Minim Invasive Gynecol. 2012;19 (5):545-553. doi:10.1016/j.jmig.2012.04.002

33. Yi MS, Kim WJ, Kim MK, et al. Effect of ultrasound-guided phrenic nerve block on shoulder pain after laparoscopic cholecystectomy-A prospective, randomized controlled trial. Surg Endosc. 2017;31(9):3637-3645. doi:10.1007/s00464-016-5398-4

34. Wada S, Fukushi Y, Nishimura M, et al. Analysis of risk factors of postlaparoscopic shoulder pain. J Obstet Gynaecol Res. 2020;46 (2):310-313. doi: $10.1111 /$ jog. 14156
Journal of Pain Research

\section{Publish your work in this journal}

The Journal of Pain Research is an international, peer reviewed, open access, online journal that welcomes laboratory and clinical findings in the fields of pain research and the prevention and management of pain. Original research, reviews, symposium reports, hypothesis formation and commentaries are all considered for publication. The manuscript

\section{Dovepress}

management system is completely online and includes a very quick and fair peer-review system, which is all easy to use. Visit http:// www.dovepress.com/testimonials.php to read real quotes from published authors. 